\title{
Erratum: In vivo imaging of neural activity
}

Weijian Yang \& Rafael Yuste

Nat. Methods 14,349-359 (2017); published online 31 March 2017; corrected after print 21 June 2017

In the version of this article initially published, the formula for $r_{z \text { confocal }}$ in Box 1 incorrectly had a coefficient of 0.4 . The correct coefficient is 1.4. The error has been corrected in the HTML and PDF versions of the article.

\section{Corrigendum: In vivo imaging of neural activity}

Weijian Yang \& Rafael Yuste

Nat. Methods 14, 349-359 (2017); published online 31 March 2017; corrected after print 21 June 2017

In the version of this article initially published, reference 76 was incorrectly classified as direct wavefront sensing. It should be classified as indirect wavefront sensing. The error has been corrected in the HTML and PDF versions of the article.

\section{Erratum: Seq-Well: portable, low-cost RNA sequencing of single cells at high throughput}

Todd M Gierahn, Marc H Wadsworth II, Travis K Hughes, Bryan D Bryson, Andrew Butler, Rahul Satija, Sarah Fortune, J Christopher Love \& Alex K Shalek

Nat. Methods 14, 395-398 (2017); published online 13 February 2017; corrected after print 21 June 2017

The doi, link, and publication date of the Seq-Well protocol in the Protocol Exchange were updated; the doi and link have been corrected from http://doi.dx.org/10.1038/protex.2017.006 to http://dx.doi.org/10.1038/protex.2017.006a, and the date has been changed from 2016 to 2017. The grant number U24 AI1 1862 was incorrect; it has been corrected to U24 AI118672. These errors have been updated in the HTML and PDF versions of the article.

\section{Erratum: Optoacoustic imaging at multiple spatiotemporal scales}

Rita Strack

Nat. Methods 14, 11 (2017); published online 29 December 2016; corrected after print 21 June 2017

In the version of this Methods in Brief initially published, the citation Deán-Ben, X.L. et al. Light Sci. Appl. 5, e16201 (2016) was incorrect. The correct citation is Deán-Ben, X.L. et al. Light Sci. Appl. 6, e16247 (2017). The error has been corrected in the HTML and PDF versions of the article. 